\title{
ODM-204, a Novel Dual Inhibitor of CYP17A1 and Androgen Receptor: Early Results from Phase I Dose Escalation in Men with Castration-resistant Prostate Cancer
}

\section{Peltola, Katriina J.}

2020-01-15

Peltola , K J , Bono , P , Hugh Jones, R, Vjaters, E, Nykänen, P, Vuorela , A, Oksala , R , Pohjanjousi , P , Mustonen, M V J , Fizazi , K \& Massard, C 2020 , ' ODM-204, a Novel Dual Inhibitor of CYP17A1 and Androgen Receptor: Early Results from Phase I Dose Escalation in Men with Castration-resistant Prostate Cancer' ', European Urology Focus , vol. 6 , no. 1 , pp. 63-70 . https://doi.org/10.1016/j.euf.2018.08.022

http://hdl.handle.net/10138/310589

https://doi.org/10.1016/j.euf.2018.08.022

cc_by_nc_nd

publishedVersion

Downloaded from Helda, University of Helsinki institutional repository.

This is an electronic reprint of the original article.

This reprint may differ from the original in pagination and typographic detail.

Please cite the original version. 


\title{
ODM-204, a Novel Dual Inhibitor of CYP17A1 and Androgen Receptor: Early Results from Phase I Dose Escalation in Men with Castration-resistant Prostate Cancer
}

\author{
Katriina J. Peltola ${ }^{a}$, Petri Bono ${ }^{a}$, Robert Hugh Jones ${ }^{b}$, Egils Vjaters $^{c}$, Pirjo Nykänen ${ }^{d}$, \\ Annamari Vuorela ${ }^{d}$, Riikka Oksala ${ }^{d}$, Pasi Pohjanjousi ${ }^{d}$, Mika V.J. Mustonen $^{d, *}$, \\ Karim Fizazi ${ }^{e}$, Christophe Massard ${ }^{f}$ \\ ${ }^{\mathrm{a}}$ Helsinki University Hospital, Comprehensive Cancer Centre, Helsinki, Finland; ${ }^{\mathrm{b}}$ Velindre Cancer Centre, Cardiff, UK; ${ }^{\mathrm{c}}$ P. Stradins Clinical University Hospital, \\ Riga, Latvia; ${ }^{\mathrm{d}}$ Orion Corporation Orion Pharma, Espoo, Finland; ${ }^{\mathrm{e}}$ Institut Gustave-Roussy, University of Paris Sud, Villejuif, France; ${ }^{\mathrm{f}}$ Drug Development \\ Department (DITEP), Inserm Unit U981, Université Paris Saclay, Université Paris-Sud, Gustave Roussy, Villejuif, France
}

\section{Article info}

Article history:

Accepted August 27, 2018

Associate Editor: Derya Tilki

Keywords:

Androgen receptor

Castration-resistant prostate

cancer

CYP17A1

ODM-204

Phase I clinical trial

\begin{abstract}
Background: Most prostate cancer patients develop castration-resistant prostate cancer (CRPC) after androgen deprivation therapy treatment. CRPC growth is mediated mostly by androgen receptor signalling driven by primary androgens synthesised largely by the CYP17A1 enzyme.

Objective: To evaluate the safety profile and dose-limiting toxicities of ODM-204. Design, setting, and participants: In this open, uncontrolled, nonrandomised, multicentre, tolerability and pharmacokinetic first-in-man phase I dose escalation study, patients with metastatic CRPC were randomised to receive ODM-204 in sequential cohorts of five dose levels (ie, 50, 100, 200, 300, and $500 \mathrm{mg}$ twice daily) concomitantly with prednisone.

Intervention: ODM-204, a novel, orally administered, investigational, nonsteroidal dual inhibitor of CYP17A1 and androgen receptor.

Outcome measurements and statistical analysis: ODM-204 plasma concentrations, serum testosterone, and prostate-specific antigen (PSA) levels were evaluated and imaging of lesions was performed.

Results and limitations: Of the 23 patients enrolled into the study, 60.9\% experienced mild adverse effects considered to be related to the study treatment, which were fatigue, increased/decreased appetite, nausea, asthenia, diarrhoea, and weight decrease. ODM204 area under the curve $\left(A_{U C} C_{0-12}\right.$ ) values increased dose dependently until the $300 \mathrm{mg}$ dose. The AUC was lower on day 8 after repeated dosing compared with day 1 from the $200 \mathrm{mg}$ dose upwards. Decreases in testosterone levels were seen with ODM-204 treatment confirming androgen deprivation. Of the patients, $13 \%$ also demonstrated a $>50 \%$ decrease in PSA at week 12 and continued ODM-204 treatment for over a year. Conclusions: ODM-204 was well tolerated up to the highest evaluated dose. There were decreases in both testosterone and PSA levels, suggesting preliminary antitumour activity in the treatment of CRPC. The pharmacokinetic properties of the molecule, however, prevent further development.

Patient summary: This study looked at the safety of ODM-204, a novel dual inhibitor of CYP17A1 and the androgen receptor, in castration-resistant prostate cancer patients. ODM-204 treatment was found to be well tolerated, and it also reduced both serum

\footnotetext{
* Corresponding author. Oncology Therapy Area, Orion Corporation Orion Pharma, Orionintie 1, P.O. Box 65, 20101 Espoo, Finland. Tel. +358 509664804. E-mail address: mika.mustonen@orionpharma.com (Mika V.J. Mustonen).
} 
testosterone and prostate-specific antigen levels, but the properties of the molecule prevent further development.

(C) 2018 European Association of Urology. Published by Elsevier B.V. This is an open access article under the CC BY-NC-ND license (http://creativecommons.org/licenses/bync-nd/4.0/).

\section{Introduction}

The androgen receptor (AR) signalling pathway plays a major role in prostate cancer (PCa), and androgen deprivation therapy (ADT) by surgical or chemical castration in addition to chemotherapy is the standard treatment for patients with advanced PCa. After initial treatment response most of the patients, however, develop castration-resistant prostate cancer (CRPC) with a poor prognosis $[1,2]$. In recent years, several clinical trials have shown that the castration-resistant growth is driven, to a large extent, by continued AR signalling, and that CRPC remains sensitive to androgens because of the sensitisation and amplification of AR signalling [3-8]. Thus, hormonal manipulation with AR blockers, in addition to steroid biosynthesis inhibitors reducing the activation of the AR-mediated pathway [9], remains the core of CRPC treatment.

Although castration leads to very low levels of circulating testosterone, androgens are still present in PCa tissues at clinically relevant concentrations that activate AR signalling and promote tumour growth [10]. Synthesis of the primary androgens testosterone and dihydrotestosterone requires a cascade of oxidative enzymes, with one of the key enzymes being CYP17A1. Consequently, CYP17A1 inhibitors have been designed for the treatment of androgen-dependent PCa. The only CYP17A1 inhibitor currently approved for the treatment of CRPC, abiraterone, has been shown to exhibit a significant overall survival benefit in a postchemotherapy phase III study, but some abiraterone-resistant tumours still continue to present persistent AR activation [11,12]. Therefore, there is a clear rationale for developing treatments that target CYP17A1 and AR together, as this may provide a more effective response than targeting either one alone.

Here, we present ODM-204, a novel, orally administered, investigational, nonsteroidal dual inhibitor of CYP17A1 and AR, which was shown to inhibit tumour growth in the murine VCaP CRPC xenograft model [13]. ODM-204 exhibits activity similar to that of galeterone towards CYP17A1 and blocks AR action to the same degree as enzalutamide. The compound was also shown to inhibit steroid biosynthesis efficiently in rodents and primates. In this phase I dose escalation study, safety profile of ODM-204 was shown to be satisfactory, but its pharmacokinetic profile would bring significant challenges on the development path.

\section{Patients and methods}

\subsection{Inclusion criteria}

Eligible patients were males over the age of $18 \mathrm{yr}$ with metastatic progressive CRPC with ongoing ADT by gonadotropin-releasing hormone agonist or antagonist, or bilateral orchiectomy, and serum testosterone level $<50 \mathrm{ng} / \mathrm{dl}$ at screening, as well as metastatic disease documented by bone scan, computed tomography, or magnetic resonance imaging, and an Eastern Cooperative Oncology Group performance status of 0-2. Disease progression was defined as rising prostate-specific antigen (PSA; progression defined by a minimum of two rising PSA levels with an interval of at least $1 \mathrm{wk}$ between them, with the screening value $\geq 2 \mathrm{ng} /$ $\mathrm{ml}$ ), soft tissue disease progression as defined by RECIST 1.1 criteria, or two or more new bone lesions. Brain lesions were exclusionary. The patients had provided written informed consent, and the study protocol was approved by independent ethics committees at each participating centre. The study was registered on ClinicalTrials.gov (NCT02344017).

\subsection{Study design and treatment}

This was an open, uncontrolled, nonrandomised, multicentre, tolerability and pharmacokinetic first-in-man phase I dose escalation study of ODM-204 in patients with progressive metastatic CRPC. Escalating dose levels of ODM-204 (50, 100, 200, 300, and $500 \mathrm{mg}$ twice daily) were administered in sequential cohorts of three to six individuals together with prednisone (Fig. 1). ODM-204 was taken orally twice a day with food (in the morning and evening), and $5 \mathrm{mg}$ of prednisone was taken once or twice a day depending on the daily dose prior to study entry. Food intake was not expected to affect the pharmacokinetics of ODM204 based on animal trials and limited phase I data. Those who did not experience any dose-limiting toxicity (DLT) within $24 \mathrm{~h}$ after the first dose continued ODM-204 treatment with b.i.d. dosing. DLTs were defined as any of the following toxicities graded according to the National Cancer Institute Common Terminology Criteria for Adverse Events determined to be related to ODM-204 and occurring during the first $28 \mathrm{~d}$ of the study treatment: grade $\geq 3$ toxicity, excluding haematological toxicities, nausea, vomiting, and diarrhoea; grade $\geq 3$ nausea, vomiting, and diarrhoea uncontrolled with antiemetic and/or antidiarrhoeal therapy; grade $\geq 3$ haematological toxicity lasting for $\geq 7$ d; grade $\geq 4$ thrombocytopenia and neutropenia; other laboratory values of $\geq$ grade 3 , which were judged clinically significant by the investigator, or any other toxicity that in the judgement of the investigator was viewed as a DLT. Once the safety of an administered dose was established, the next dose level was administered, and the patients with previous dose level were allowed to continue treatment with ODM204 until progression or intolerable adverse events (AEs). The next dose level was started after a minimum of three patients had completed $28 \mathrm{~d}$ of treatment and after safety review by the safety monitoring board.

\subsection{Pharmacokinetic assessments}

On day 1 , blood samples were taken before dose and at $0.5,1,1.5,2,2.5,3$, $4,5,6,8,12$, and $24 \mathrm{~h}$ after single dosing. On day 8 after repeated dosing, blood samples were taken before dose and at $0.5,1,1.5,2,2.5,3,4,6,8$, and $12 \mathrm{~h}$. Plasma concentrations of ODM-204 were determined from the blood samples using liquid chromatography with tandem mass spectrometry. The area under the curve (AUC) from time zero to $12 \mathrm{~h}, 24 \mathrm{~h}$, and infinity; maximum concentration $\left(C_{\max }\right)$; time to reach maximum concentration $\left(t_{\max }\right)$; and elimination half-life $\left(t_{1} / 2\right)$ were calculated using Phoenix WinNonlin software (Certara, Princeton, NJ, USA). 


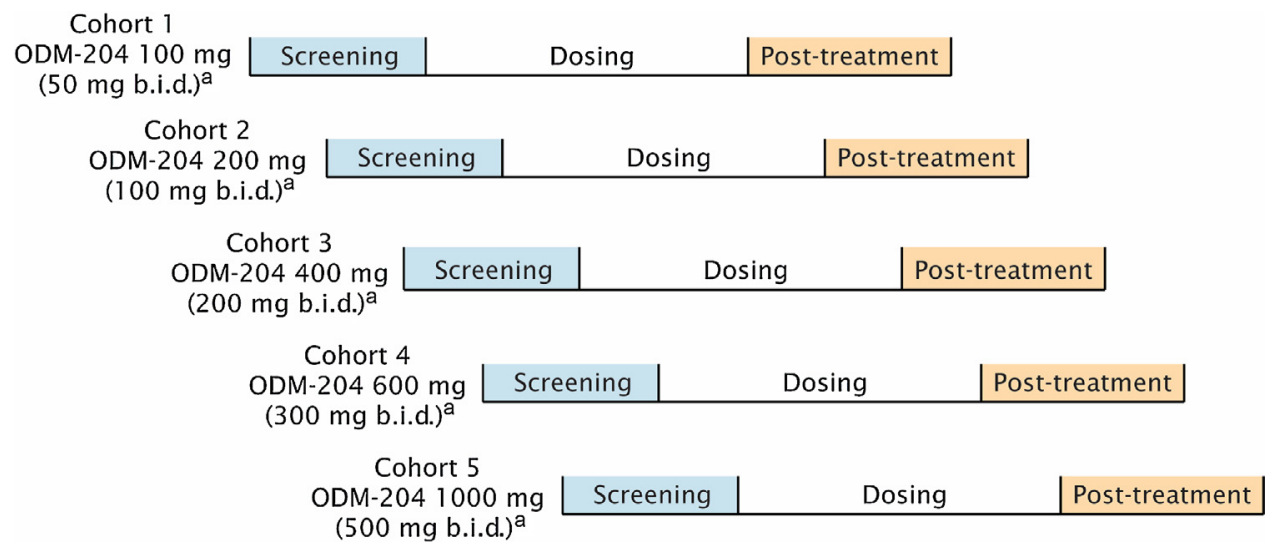

Fig. 1 - Study design. ${ }^{a}$ On day 1 only the morning dose of ODM-204 was administered. From day 1 onward oDM-204 was taken b.i.d.

\subsection{Antitumour activity}

Serum total PSA concentration was determined every 4 wk until 24 wk and every $12 \mathrm{wk}$ thereafter. In case of PSA progression, a confirmatory test was obtained 3-4 wk later. PSA response and progression were evaluated using PCWG2 criteria for PSA progression.

Testosterone concentrations were measured from blood samples on days 1,8 , and 29 after start of treatment, as well as on week 12, week 24, and every $12 \mathrm{wk}$ thereafter.

Chest, abdomen, and pelvic CT or MRI (as per investigator's discretion) was performed at screening, week 12 , and every $12 \mathrm{wk}$ thereafter to evaluate soft tissue disease progression as defined by RECIST 1.1 criteria.

\subsection{Statistical considerations}

AEs reported after administration of the study treatment were classified by system organ classes and preferred terms using the MedDRA dictionary. The number and proportion (\%) of patients experiencing each $\mathrm{AE}$ was tabulated. The AEs were graded by severity and causality. PK parameters were analysed after logarithm transformation, and 95\% confidence interval for the geometric mean were calculated. Descriptive statistics for continuous variables were as follows: number of observations (N), mean (MEAN), standard deviation (SD), minimum (MIN), median, and maximum (MAX). In PK variables also geometric mean (GMEAN) and coefficient of variation (CV) was calculated. In log-normal distribution, the formula $\mathrm{CV}=100 \times$ square root (exp [variance of logtransformed data] - 1) was used:

$\mathrm{CV}=100 \times \sqrt{\exp ^{\text {varianceoflog-transformeddata }-1}}$

\section{Results}

\subsection{Patient characteristics and study drug exposure}

In total, 23 patients with CRPC were enrolled into the study between 17 February 2015 and 22 June 2016, at four centres: three into the $50 \mathrm{mg}$ twice daily, three into the $100 \mathrm{mg}$ twice daily, six into the $200 \mathrm{mg}$ twice daily, seven into the $300 \mathrm{mg}$ twice daily, and four into the $500 \mathrm{mg}$ twice daily dose level groups. The cut-off date for the data included in this report was 21 December 2017. Baseline demographics and disease characteristics are shown in Table 1 . Median time on treatment was $12.1 \mathrm{wk}(0.3-71.7 \mathrm{wk})$. Nine (39\%) patients continued treatment for more than $12 \mathrm{wk}$, and four (17\%) were still receiving treatment at the time of data cut-off.

\subsection{Adverse events}

AEs were reported in all the 23 patients, and in 14 of these patients (61\%) these AEs were considered to be related to the study treatment. Of the patients, 22 (95\%) suffered mild grade 1 AEs, 13 (57\%) suffered moderate grade 2 AEs, and seven (30\%) suffered severe or life-threatening grade 3-4 AEs. Of the serious AEs, three (13\%) were considered related to study treatment. The most common treatment-related AEs were fatigue (22\%), increased appetite (17\%), nausea (17\%), asthenia (9\%), diarrhoea (9\%), decreased appetite (9\%), and weight decrease (9\%). In 10 of the patients (43\%), disease progression-related AEs led to discontinuation from the study, while six (26\%) patients were discontinued due to disease progression, two (9\%) due to DLTs (drug hypersensitivity in one patient in the $300 \mathrm{mg}$ cohort, and vomiting and nausea in one patient in the $200 \mathrm{mg}$ cohort), and four (17\%) due to reasons classified as "other". One patient in the $300 \mathrm{mg}$ cohort died during the study period due to disease progression. In general, the occurrence of AEs was not deemed to be dose dependent, as treatment-related AEs, serious AEs, and discontinuations due to AEs were present in all the study groups in similar proportions. The most commonly reported AEs and their severity are shown in Table 2 .

\subsection{Pharmacokinetics}

Pharmacokinetic parameters for ODM-204 were determined on days 1 and 8 . On day 1 , the $A C_{0-12}$ of ODM204 increased in a dose-dependent manner up to the $300 \mathrm{mg}$ dose. At the $500 \mathrm{mg}$ dose level, a slight decrease in $\mathrm{AUC}_{0-12}$ was observed (Fig. $2 \mathrm{~A}$ ). On day 8, $\mathrm{AUC}_{0-12}$ increased up to the $300 \mathrm{mg}$ twice daily dose, with a slight decrease between the 100 and $200 \mathrm{mg}$ twice daily doses and a remarkable decrease at the $500 \mathrm{mg}$ twice daily dose level. Notably, the $\mathrm{AUC}_{0-12}$ values were also greater on day $1 \mathrm{com}-$ pared with day 8 from the $200 \mathrm{mg}$ dose twice daily 
Table 1 - Patient characteristics at baseline.

\begin{tabular}{|c|c|c|c|c|c|c|}
\hline \multirow[t]{2}{*}{ Characteristics } & \multicolumn{5}{|c|}{ Total daily dose $\mathrm{e}^{\mathrm{a}}$} & \multirow{2}{*}{$\begin{array}{r}\text { Total } \\
(N=23)\end{array}$} \\
\hline & $\begin{array}{l}100 \mathrm{mg} \\
(N=3)\end{array}$ & $\begin{array}{l}200 \mathrm{mg} \\
(N=3)\end{array}$ & $\begin{array}{l}400 \mathrm{mg} \\
(N=6)\end{array}$ & $\begin{array}{c}600 \mathrm{mg} \\
(N=7)\end{array}$ & $\begin{array}{c}1000 \mathrm{mg} \\
(N=4)\end{array}$ & \\
\hline Median age (range), yr & $74(66-76)$ & $70(59-77)$ & $68.5(61-75)$ & $69(57-84)$ & $71(66-74)$ & $70(57-84)$ \\
\hline \multicolumn{7}{|l|}{ ECOG, $n(\%)$} \\
\hline 0 & $1(33)$ & $1(33)$ & $4(67)$ & $3(43)$ & $3(75)$ & $12(52)$ \\
\hline 1 & $2(67)$ & $2(67)$ & $2(33)$ & $4(57)$ & $1(25)$ & $11(48)$ \\
\hline \multicolumn{7}{|l|}{ BMI $\left(\mathrm{kg} / \mathrm{m}^{2}\right)$} \\
\hline Median & 25.1 & 30.8 & 31.5 & 29.7 & 27.4 & 29.8 \\
\hline$(\min -m a x)$ & $(24-32)$ & $(26-31)$ & $(25-40)$ & $(21-32)$ & $(25-37)$ & $(21-40)$ \\
\hline \multicolumn{7}{|l|}{ PSA (ng/ml) } \\
\hline Median & 149.6 & 50.0 & 26.7 & 94.4 & 19.1 & 46.5 \\
\hline$(\min -\max )$ & $(68.3-162.3)$ & $(14.5-210.9)$ & $(5.5-249.6)$ & $(7.2-194.7)$ & $(0.7-36.5)$ & $(0.7-249.6)$ \\
\hline \multicolumn{7}{|l|}{ Gleason score } \\
\hline Low $(2-4)$ & $0(0)$ & $1(33)$ & $0(0)$ & $0(0)$ & $0(0)$ & $1(4)$ \\
\hline Medium (5-7) & $1(33)$ & $0(0)$ & $3(50)$ & $3(43)$ & $1(25)$ & $8(35)$ \\
\hline High $(8-10)$ & $2(67)$ & $2(67)$ & $3(50)$ & $3(43)$ & $3(75)$ & $13(57)$ \\
\hline \multicolumn{7}{|l|}{ Previous therapies, $n$ (\%) } \\
\hline Chemotherapy & $1(33)$ & $2(67)$ & $2(33)$ & $5(71)$ & $3(75)$ & $10(43)$ \\
\hline Abiraterone & $0(0)$ & $1(33)$ & $2(33)$ & $2(29)$ & $3(75)$ & $8(35)$ \\
\hline Enzalutamide & $0(0)$ & $1(33)$ & $2(33)$ & $5(71)$ & $3(75)$ & $4(17)$ \\
\hline
\end{tabular}

upwards. The $C_{\max }$ values on both day 1 and day 8 reflected in general the respective $\mathrm{AUC}_{0-12}$ values (Fig. $2 \mathrm{~B}$ ).

\subsection{Testosterone changes}

Testosterone decreases of over $50 \%$ compared with baseline were observed in all the studied doses after 8 d ODM-204 treatment, with a decrease of over $75 \%$ present in some patients in the 50,300 , and $500 \mathrm{mg}$ twice daily dose groups (Fig. 3). However, the testosterone decrease was not dose dependent and all cohorts (except the $50 \mathrm{mg}$ cohort) included patients who did not present testosterone decrease. The majority of the maximum testosterone decreases, including all the decreases over $50 \%$, were seen on day 8 , after which testosterone levels started to increase back to the baseline in most patients (Supplementary Table 1).

\subsection{PSA changes}

PSA decreases were seen in seven (30\%) patients at week 4, and the median decrease was $47 \%$ (2-99\%). At week 12 , three (13\%) patients had PSA response with a $50 \%$ or higher reduction from baseline (Fig. 4). Out of the seven patients who showed a PSA decrease at week 4, six continued ODM204 treatment for at least $24 \mathrm{wk}$ without discontinuation due to an AE or disease progression, and three continued in the study for more than a year (Fig. 5). Interestingly, one patient continued ODM-204 treatment for over $36 \mathrm{wk}$ without any initial PSA decrease, and three of the patients (patient ID: 2, 4, and 6; Fig. 5) who had demonstrated initial PSA decrease were not discontinued from the study until several weeks after the point at which the PSA decrease had ended. The median time of ODM-204 treatment across cohorts was $12.14 \mathrm{wk}$.
Imaging results of prostate lesions at week 12 showed that ODM-204 treatment resulted in a stable disease in one patient in the each of the 50 and $200 \mathrm{mg}$ twice daily groups and in two patients in the $500 \mathrm{mg}$ twice daily group. Additionally, ODM-204 treatment also resulted in a stable disease regarding bone lesions in one patient in all the studied dose cohorts, except in the $200 \mathrm{mg}$ twice daily cohort where four patients were reported to have a stable disease bone response.

\section{Discussion}

In this first-in-man dose escalation trial, ODM-204 was demonstrated to be generally well tolerated in CRPC patients, with doses up to $500 \mathrm{mg}$ twice daily. One DLT occurred at the $300 \mathrm{mg}$ twice daily cohort, but a maximum tolerated dose was not reached. The dose escalation was discontinued at the $500 \mathrm{mg}$ twice daily dose level because of decreased ODM-204 plasma concentrations at higher dose levels after repeated dosing on day 8 compared with single dosing on day 1 . The most common treatment-related AEs, fatigue, increased/decreased appetite, nausea, asthenia, diarrhoea, and weight decrease, were generally of grade 1 and 2 in severity and without significant clinical consequence. The AE profile did not differ between dose levels. These AEs are in line with previous observations showing that AR inhibitors such as enzalutamide are associated with fatigue and gastrointestinal events [14,15]. Interestingly, ODM-204 treatment did not demonstrate cardiac AEs, which have been associated with the CYP17A1 inhibitor abiraterone [14]. Additionally, the incidence and severity did not appear to be directly related to the dose or differences in the ODM-204 plasma concentration.

Interpretation of antitumour activity can be difficult in the setting of a phase I trial given that cohorts are small and 
Table 2 - Most common adverse events by dose (patient count and percentage).

\begin{tabular}{|c|c|c|c|c|c|c|}
\hline \multirow[t]{2}{*}{ Adverse event, $n$ (\%) } & \multicolumn{5}{|c|}{ Daily total dose ${ }^{a}$} & \multirow{2}{*}{$\begin{array}{l}\text { Total } \\
(N=23)\end{array}$} \\
\hline & $\begin{array}{l}100 \mathrm{mg} \\
(N=3)\end{array}$ & $\begin{array}{c}200 \mathrm{mg} \\
(N=3)\end{array}$ & $\begin{array}{l}400 \mathrm{mg} \\
(N=6)\end{array}$ & $\begin{array}{l}600 \mathrm{mg} \\
(N=7)\end{array}$ & $\begin{array}{c}1000 \mathrm{mg} \\
(N=4)\end{array}$ & \\
\hline Decreased appetite & & $2(67)$ & & $3(43)$ & $1(25)$ & $6(26)$ \\
\hline Grade 1 & & $1(33)$ & & $3(43)$ & $1(25)$ & $5(22)$ \\
\hline Grade 2 & & $1(33)$ & & & & $1(4)$ \\
\hline Fatigue & $1(33)$ & $1(33)$ & $2(33)$ & $1(14)$ & $1(25)$ & $6(26)$ \\
\hline Grade 1 & $1(33)$ & $1(33)$ & & $1(14)$ & $1(25)$ & $4(17)$ \\
\hline Grade 2 & & & $2(33)$ & & & $2(9)$ \\
\hline Nausea & & $1(33)$ & $2(33)$ & $2(29)$ & $1(25)$ & $6(26)$ \\
\hline Grade 1 & & $1(33)$ & & & $1(25)$ & $2(9)$ \\
\hline Grade 2 & & & $1(17)$ & $2(29)$ & & $3(13)$ \\
\hline Grade 3 & & & $1(17)$ & & & $1(4)$ \\
\hline Diarrhoea & & $1(33)$ & $2(33)$ & $2(29)$ & & $5(22)$ \\
\hline Grade 1 & & $1(33)$ & $1(17)$ & $2(29)$ & & $4(17)$ \\
\hline Grade 3 & & & $1(17)$ & & & $1(4)$ \\
\hline Vomiting & & $1(33)$ & $1(17)$ & $2(29)$ & $1(25)$ & $5(22)$ \\
\hline Grade 1 & & $1(33)$ & & $2(29)$ & $1(25)$ & $4(17)$ \\
\hline Grade 3 & & & $1(17)$ & & & $1(4)$ \\
\hline Asthenia & & $1(33)$ & $1(17)$ & $3(43)$ & & $5(22)$ \\
\hline Grade 1 & & & $1(17)$ & $1(14)$ & & $2(9)$ \\
\hline Grade 2 & & $1(33)$ & & $2(29)$ & & $3(13)$ \\
\hline Constipation & & $1(33)$ & $1(17)$ & $1(14)$ & $1(25)$ & $4(17)$ \\
\hline Grade 1 & & & $1(17)$ & $1(14)$ & $1(25)$ & $3(13)$ \\
\hline Grade 2 & & $1(33)$ & & & & $1(4)$ \\
\hline Insomnia & & & $1(17)$ & $2(29)$ & $1(25)$ & $4(17)$ \\
\hline Grade 1 & & & $1(17)$ & $2(29)$ & $1(25)$ & $4(17)$ \\
\hline Weight decrease & & & $1(17)$ & $1(14)$ & $2(50)$ & $4(17)$ \\
\hline Grade 1 & & & $1(17)$ & $1(14)$ & $2(50)$ & $4(17)$ \\
\hline Abdominal pain & & & & $2(29)$ & $1(25)$ & $3(13)$ \\
\hline Grade 1 & & & & $1(14)$ & $1(25)$ & $2(9)$ \\
\hline Grade 2 & & & & $1(14)$ & & $1(4)$ \\
\hline Back pain & & & $1(17)$ & & $2(50)$ & $3(13)$ \\
\hline Grade 1 & & & $1(17)$ & & $2(50)$ & $3(13)$ \\
\hline Blood potassium decrease & & & $1(17)$ & $1(14)$ & $1(25)$ & $3(13)$ \\
\hline Grade 1 & & & & & $1(25)$ & $1(4)$ \\
\hline Grade 2 & & & $1(17)$ & $1(14)$ & & $2(9)$ \\
\hline Depressed mood & & $1(33)$ & & $1(14)$ & $1(25)$ & $3(13)$ \\
\hline Grade 1 & & $1(33)$ & & $1(14)$ & $1(25)$ & $3(13)$ \\
\hline Pain in extremity & $1(33)$ & $1(33)$ & $1(17)$ & & & $3(13)$ \\
\hline Grade 1 & & $1(33)$ & $1(17)$ & & & $2(9)$ \\
\hline Grade 2 & $1(33)$ & & & & & $1(4)$ \\
\hline
\end{tabular}

doses are variable, but the current study provided some indication of the efficacy of ODM-204. Firstly, ODM-204 treatment resulted in a decrease of serum testosterone levels in most of the patients in all the studied dose cohorts. As serum testosterone level monitoring is commonly used

A

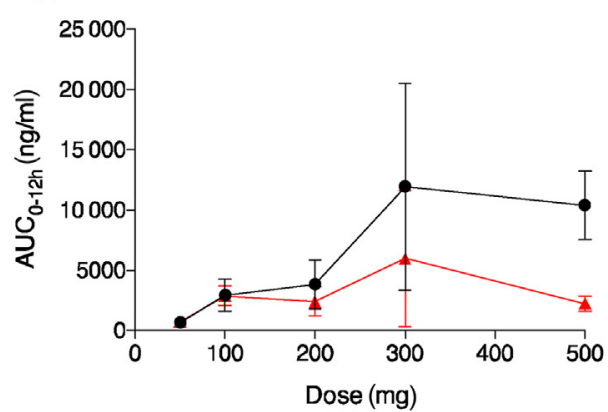

to verify response to ADT [16], this confirms the androgen deprivation effect of ODM-204. Secondly, serum PSA levels were also decreased by ODM-204 treatment in 30\% of the patients, with $13 \%$ showing a decrease of over $50 \%$ compared with the baseline. The decrease of serum PSA levels

B
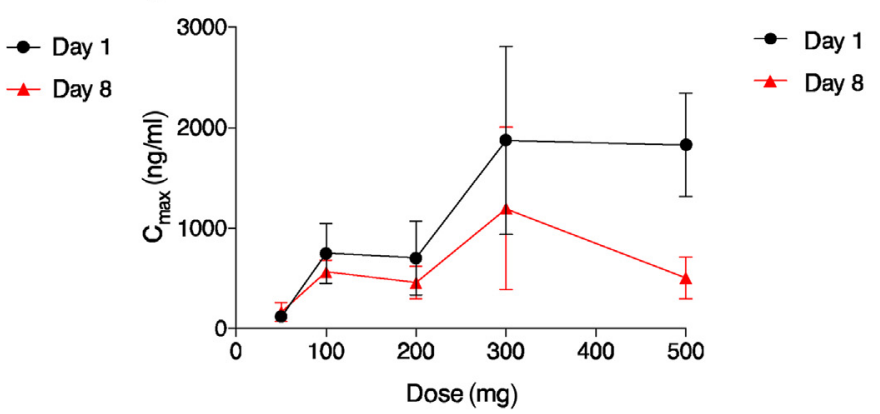

Fig. 2 - Pharmacokinetics of ODM-204. (A) $A U C_{0-12}$ and (B) $C_{\max }$ versus dose, mean + SD. AUC = area under the curve; SD = standard deviation. 


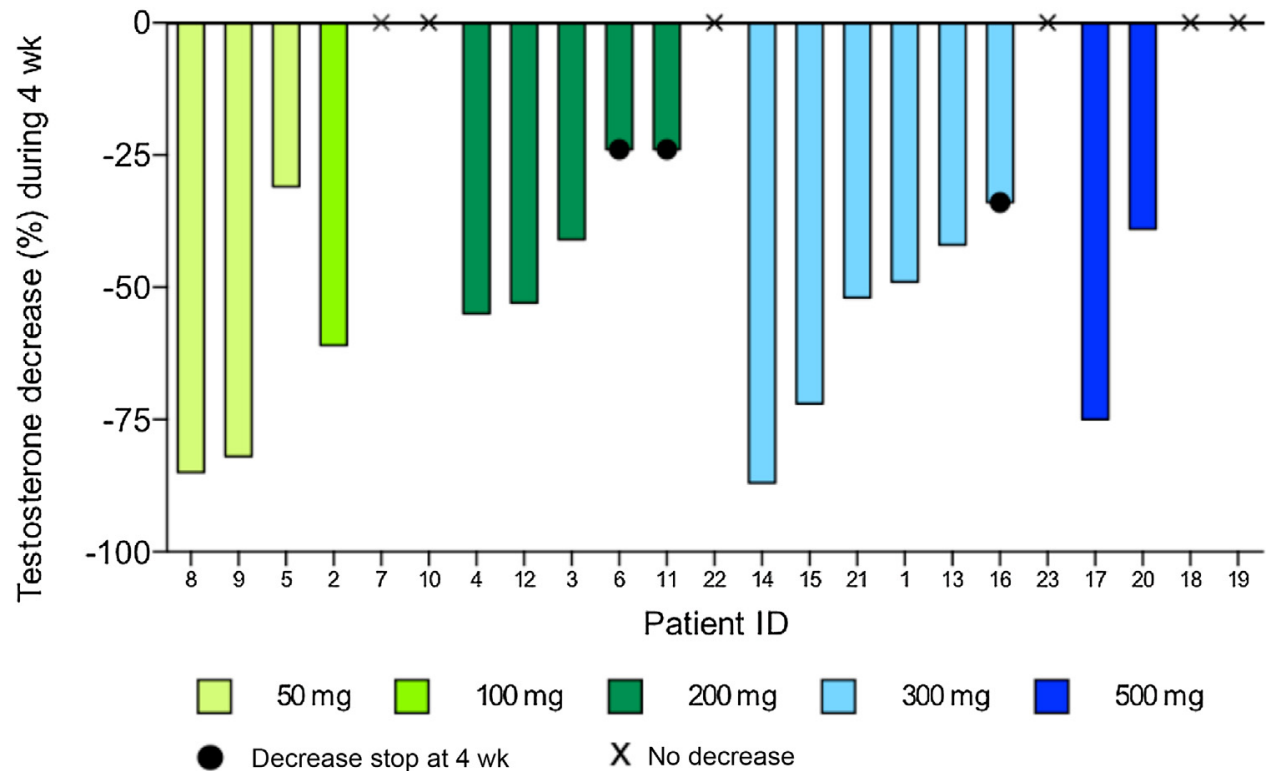

Fig. 3 - Maximum testosterone changes during the first 4 wk compared with baseline.

may not, however, reflect the efficacy of ODM-204 accurately because the study included many patients with prior use of enzalutamide and abiraterone. This may cause cross resistance as they are also AR pathway inhibitors with similar modes of action. Additionally, metabolites of abiraterone may also inhibit the AR pathway [17]. Thirdly, imaging results showed that ODM-204 treatment resulted in a stable disease in four patients at week 12 as well as the arrest of bone lesion progressing in at least one patient in each dose cohort. Importantly, the patients demonstrating $>50 \%$ decrease in PSA continued ODM-204 treatment for over a year without discontinuation due to an AE or disease progression, which is an encouraging outcome. Taken together, these data suggest that dual inhibition of CYP17A1 and AR could be a valuable mechanism for the treatment of PCa patients [18].

Interestingly, the AUC (from the $200 \mathrm{mg}$ dose upwards) and $C_{\max }$ values of ODM-204 were unexpectedly greater on day 1 compared with those on day 8 , contrary to what has been observed in the nonclinical studies in monkeys. At the $500 \mathrm{mg}$ dose level, decreases in AUC values were also observed on both day 1 and day 8, suggesting a decrease in the steady-state plasma concentration of ODM-204. ODM-204 is mainly eliminated via the CYP3A4 enzyme, and thus this effect may be related to an induction of the CYP3A4 elimination route, which seems to become pronounced especially at higher doses after an 8-d exposure to ODM-204. If so, the patients who have less decrease in

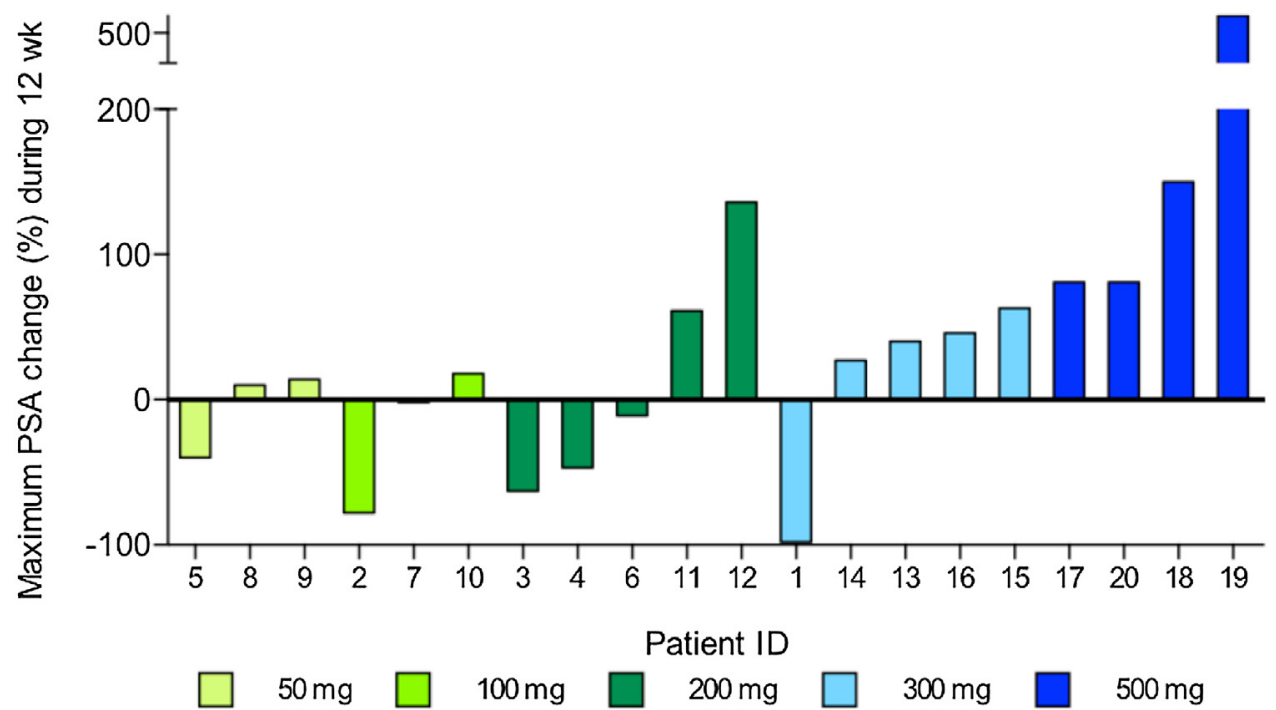

Fig. 4 - Maximum PSA change (\%) from baseline during 12 wk. PSA = prostate-specific antigen. 


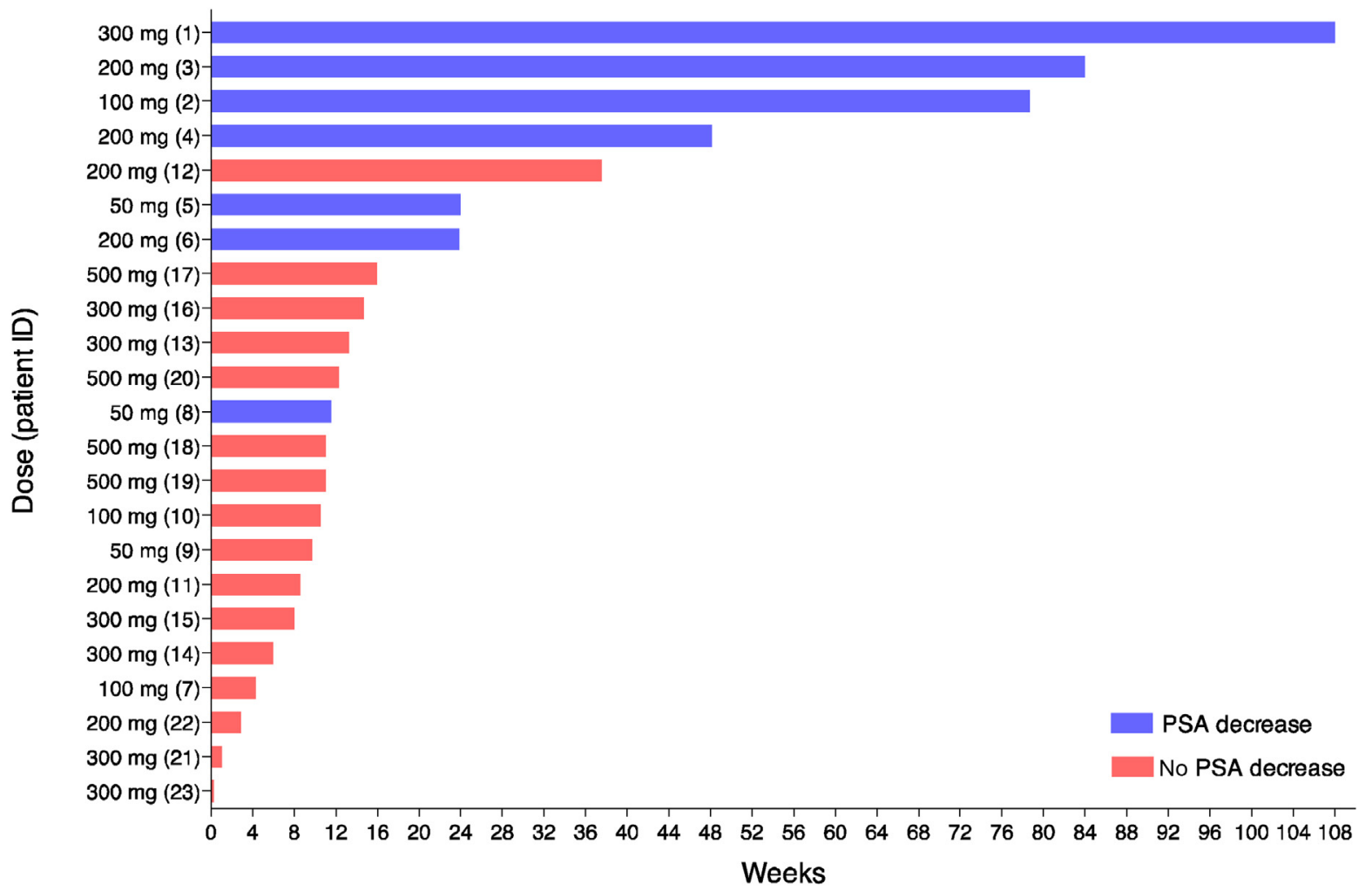

Fig. 5 - Duration of ODM-204 treatment. Time in weeks spent in the study without discontinuation due to an AE or disease progression. Blue bars denote patients who demonstrated PSA decrease, and red bars denote patients who did not. $A E=$ adverse event; $P S A=$ prostate-specific antigen.

steady-state plasma concentrations should have better outcomes; interestingly, the patient (dosed $300 \mathrm{mg}$ twice a day) who had both the highest plasma concentrations and the lowest decrease in AUC by day 8 used the CYP3A4 inhibitor ezetimibe [19]. Hence, the pharmacokinetic properties make further development of the molecule challenging.

\section{Conclusions}

In conclusion, ODM-204 demonstrated an acceptable safety profile up to the highest tested dose of $500 \mathrm{mg}$ twice daily as well as preliminary antitumour activity in some patients. Based on this study, no new trials are currently being planned with ODM-204.

Author contributions: Mika V.J. Mustonen had full access to all the data in the study and takes responsibility for the integrity of the data and the accuracy of the data analysis.

Study concept and design: Fizazi, Mustonen, Bono.

Acquisition of data: Peltola, Bono, Jones, Vjaters, Fizazi, Massard.

Analysis and interpretation of data: Peltola, Bono, Jones, Vjaters, Nykänen, Vuorela, Oksala, Pohjanjousi, Mustonen, Fizazi, Massard.

Drafting of the manuscript: Peltola, Bono, Pohjanjousi, Mustonen, Fizazi, Massard.

Critical revision of the manuscript for important intellectual content: Peltola, Bono, Mustonen, Massard.

Statistical analysis: Pohjanjousi.

Obtaining funding: Nykänen, Vuorela, Oksala, Pohjanjousi, Mustonen.
Administrative, technical, or material support: Nykänen, Vuorela, Pohjanjousi, Mustonen.

Supervision: Bono, Mustonen, Fizazi, Massard.

Other: None.

Financial disclosures: Mika V.J. Mustonen certifies that all conflicts of interest, including specific financial interests and relationships and affiliations relevant to the subject matter or materials discussed in the manuscript (eg, employment/affiliation, grants or funding, consultancies, honoraria, stock ownership or options, expert testimony, royalties, or patents filed, received, or pending), are the following: Dr. Peltola reports personal fees from Orion Pharma, BMS, Pfizer, Roche, MSD, and Ipsen outside the submitted work, and is a stock holder in Faron Pharmaceuticals. Dr, Bono reports honoraria from Orion Pharma during the conduct of the study, and honoraria from Pfizer, MSD, BMS, Novartis, and Ipsen outside the submitted work. Dr. Nykänen, Dr. Vuorela, Dr. Oksala, Dr. Pohjanjousi, and Dr. Mustonen are employees of Orion Corporation Orion Pharma. Dr. Fizazi reports participation to advisory boards and honoraria from Amgen, Astellas, Bayer, Jansen, Sanofi, and Orion outside the submitted work. Dr. Massard reports participation to advisory boards of, payment for speaker bureau from, and investigator in Amgen, Astellas, Astra Zeneca, Bayer, Celgene, Genentech, Ipsen, Jansen, Lilly, Novartis, Pfizer, Roche, Sanofi, and Orion outside the submitted work. Dr. Jones has declared no conflicts of interest.

Funding/Support and role of the sponsor: This work was supported by Orion Corporation Orion Pharma.

Acknowledgements: We thank all patients and their families for participating in this trial. We further thank all sites and their personnel, and PSI CRO AG. Aurexel Life Sciences Ltd (www.aurexel.com) is acknowledged for the editorial support funded by the Hospital District of Helsinki and Uusimaa. 


\section{Appendix A. Supplementary data}

Supplementary data associated with this article can be found, in the online version, at https://doi.org/10.1016/j.euf. 2018.08.022.

\section{References}

[1] Kirby M, Hirst C, Crawford ED. Characterising the castration-resistant prostate cancer population: a systematic review. Int J Clin Pract 2011;65:1180-92.

[2] Gillessen S, Attard G, Beer TM, et al. Management of patients with advanced prostate cancer: the report of the Advanced Prostate Cancer Consensus Conference APCCC 2017. Eur Urol 2018;73:178-211.

[3] Linja MJ, Savinainen KJ, Saramaki OR, Tammela TL, Vessella RL, Visakorpi T. Amplification and overexpression of androgen receptor gene in hormone-refractory prostate cancer. Cancer Res 2001;61:3550-5.

[4] Scher HI, Sawyers CL. Biology of progressive, castration-resistant prostate cancer: directed therapies targeting the androgen-receptor signaling axis. J Clin Oncol 2005;23:8253-61.

[5] Bubendorf L, Kononen J, Koivisto P, et al. Survey of gene amplifications during prostate cancer progression by high-throughput fluorescence in situ hybridization on tissue microarrays. Cancer Res 1999;59:803-6.

[6] Visakorpi T, Hyytinen E, Koivisto P, et al. In vivo amplification of the androgen receptor gene and progression of human prostate cancer. Nat Genet 1995;9:401-6.

[7] Waltering KK, Urbanucci A, Visakorpi T. Androgen receptor (AR) aberrations in castration-resistant prostate cancer. Mol Cell Endocrinol 2012;360:38-43.

[8] Grasso CS, Wu YM, Robinson DR, et al. The mutational landscape of lethal castration-resistant prostate cancer. Nature 2012;487:239-43.
[9] de Bono JS, Logothetis CJ, Molina A, et al. Abiraterone and increased survival in metastatic prostate cancer. N Engl J Med 2011;364:19952005.

[10] Mohler JL, Gaston KE, Moore DT, et al. Racial differences in prostate androgen levels in men with clinically localized prostate cancer. J Urol 2004;171(6 Pt 1):2277-80.

[11] Mostaghel EA. Abiraterone in the treatment of metastatic castration-resistant prostate cancer. Cancer Manag Res 2014;6:39-51.

[12] Sharifi N, Auchus RJ. Androstenedione is the preferred androgen source in hormone refractory prostate cancer-letter. Clinical Cancer Res 2014;20:4971.

[13] Oksala R, Moilanen A, Riikonen R, et al. Discovery and development of ODM-204: a novel nonsteroidal compound for the treatment of castration-resistant prostate cancer by blocking the androgen receptor and inhibiting CYP17A1. J Steroid Biochem Mol Biol. In press, corrected proof. https://doi.org/10.1016/j.jsbmb.2018.02.004

[14] Moreira RB, Debiasi M, Francini E, et al. Differential side effects profile in patients with $\mathrm{MCRPC}$ treated with abiraterone or enzalutamide: a meta-analysis of randomized controlled trials. Oncotarget 2017;8:84572-8.

[15] Rathkopf DE, Smith MR, de Bono JS, et al. Updated interim efficacy analysis and long-term safety of abiraterone acetate in metastatic castration-resistant prostate cancer patients without prior chemotherapy (COU-AA-302). Eur Urol 2014;66:815-25.

[16] Schulman CC, Irani J, Morote J, et al. Testosterone measurement in patients with prostate cancer. Eur Urol 2010;58:65-74.

[17] Li Z, Alyamani M, Li J, et al. Redirecting abiraterone metabolism to fine-tune prostate cancer anti-androgen therapy. Nature 2016;533:547-51.

[18] Efstathiou E, Titus M, Wen S, et al. Molecular characterization of enzalutamide-treated bone metastatic castration-resistant prostate cancer. Eur Urol 2015;67:53-60.

[19] Suchy D, Labuzek K, Stadnicki A, Okopien B. Ezetimibe-a new approach in hypercholesterolemia management. Pharmacol Rep 2011;63:1335-48. 